\title{
Anharmonic Spectroscopic Investigation of Tellurophene and Its Perdeuterated Isotopomer: Application of Second-Order Perturbation Theory
}

\author{
Andrea Alparone \\ Department of Chemistry, University of Catania, Viale A. Doria 6, 95125 Catania, Italy \\ Correspondence should be addressed to Andrea Alparone; agalparone@gmail.com
}

Received 15 July 2013; Revised 25 September 2013; Accepted 25 September 2013; Published 2 January 2014

Academic Editor: Daniel Glossman-Mitnik

Copyright (C) 2014 Andrea Alparone. This is an open access article distributed under the Creative Commons Attribution License, which permits unrestricted use, distribution, and reproduction in any medium, provided the original work is properly cited.

\begin{abstract}
Vibrational spectra of tellurophene and of its perdeuterated isotopomer were computed using the DFT-B3LYP functional with the LANL2DZ(d,p) basis set. The frequencies of fundamental and overtone transitions were obtained in vacuum under the harmonic approximation and anharmonic second-order perturbation theory (PT2). On the whole the anharmonic corrections reduce the harmonic wavenumber values, in many cases better reproducing the observed fundamental frequencies. The largest anharmonic effects are found for the $\mathrm{C}-\mathrm{H}$ and $\mathrm{C}-\mathrm{D}$ stretching vibrations, characterized by relatively high anharmonic coupling constants (up to $\mathrm{ca} .120 \mathrm{~cm}^{-1}$ ). For the $\mathrm{C}-\mathrm{H} / \mathrm{C}-\mathrm{D}$ stretches, the harmonic $\mathrm{H} \rightarrow \mathrm{D}$ isotopic frequency red-shifts overestimate the observed data by $47-63 \mathrm{~cm}^{-1}$ (5.9-8.1\%), whereas the PT2 computations exhibit significantly better performances, predicting the experimental data within $1-19 \mathrm{~cm}^{-1}(0.1-2.4 \%)$.
\end{abstract}

\section{Introduction}

Tellurophene is a five-membered heterocycle $\left(\mathrm{C}_{4} \mathrm{H}_{4} \mathrm{Te}\right.$, Figure 1) homologue of the furan molecule. Tellurophenebased compounds have received great attention for the development and fabrication of promising polymeric conductors $[1,2]$ and nonlinear optical materials [3-8]. The experimental structure of $\mathrm{C}_{4} \mathrm{H}_{4} \mathrm{Te}$ is available from microwave measurements [9], whereas the infrared and Raman spectra of $\mathrm{C}_{4} \mathrm{H}_{4} \mathrm{Te}$ and of its perdeuterated isotopomer $\left(\mathrm{C}_{4} \mathrm{D}_{4} \mathrm{Te}\right)$ were recorded in various phases [10-14]. On the theoretical side, the vibrational spectra of $\mathrm{C}_{4} \mathrm{H}_{4} \mathrm{Te}$ were previously calculated in vacuum under the harmonic approximation by using Hartree-Fock [7] and Density Functional Theory (DFT) computations [15]. However, as well-known in the literature, the harmonic treatment often overestimates experimental wavenumbers of fundamentals and overtones, in particular, of the highest-energy spectral regions [16]. To partially circumvent this deficiency, harmonic frequencies can be corrected through scaling procedures $[17,18]$ or direct anharmonic calculations [19-21]. Anharmonic terms are usually calculated by means of variational [19] or perturbative [20,21] treatments. As established in the literature [22], the perturbative methods are less accurate than the variational ones. Nevertheless, many recent results attest satisfactory performances of the perturbative methodologies, especially for the prediction of anharmonic contributions to fundamentals and overtones of cyclic compounds [22-30].

In this work we investigate the effects of the anharmonic corrections on the vibrational wavenumbers of fundamental and overtone transitions of $\mathrm{C}_{4} \mathrm{H}_{4} \mathrm{Te}$ and $\mathrm{C}_{4} \mathrm{D}_{4} \mathrm{Te}$. The anharmonic terms were predicted in the gas phase using the second-order perturbation theory (PT2) as described in detail by Barone [20]. The calculations were performed using the hybrid three-parameters B3LYP DFT method [31, 32] with the LANL2DZ(d,p) basis set [33, 34]. Anharmonic PT2DFT spectra have been previously reported for the congeners furan [22, 25], thiophene [22], and more recently selenophene [30]. To the best of our knowledge, anharmonic theoretical wavenumbers of fundamental and overtone transitions of tellurophene and its perdeuterated isotopomer have been computed here for the first time. 


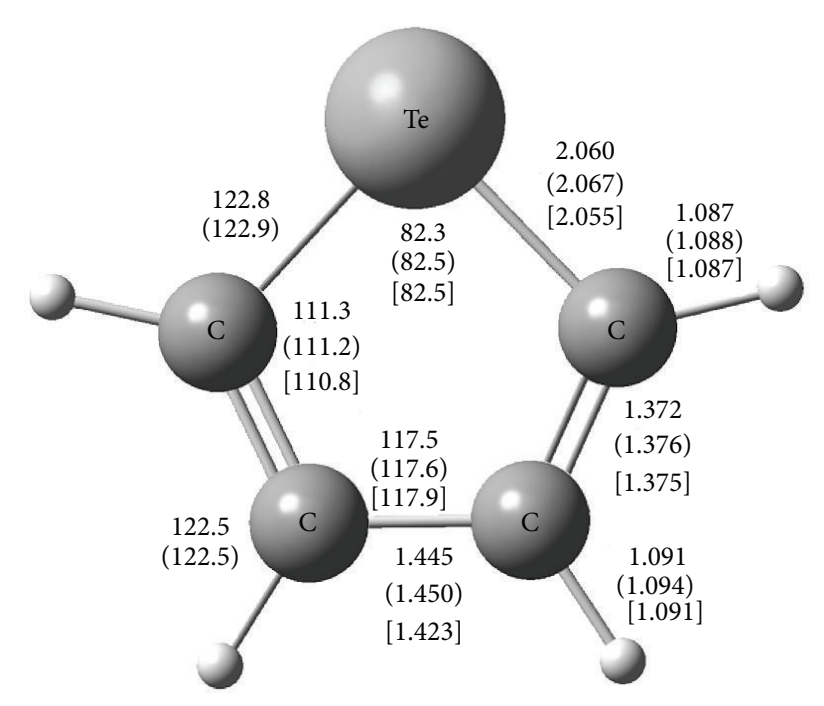

FIGURE 1: B3LYP/LANL2DZ(d,p) geometrical parameters $\left(r_{e}\right.$ structure) of tellurophene. The data reported in the round brackets refer to the B3LYP/LANL2DZ(d,p) vibrationally averaged geometry $\left(r_{z}\right.$ structure). The data reported in the square brackets refer to the experimental geometry [9].

\section{Computational Details}

The current computations were exclusively performed with the GAUSSIAN 09 package [35]. The structure of $\mathrm{C}_{4} \mathrm{H}_{4} \mathrm{Te}$ were fully optimized under the $\mathrm{C}_{2 \mathrm{v}}$ point group symmetry using the B3LYP functional with the LANL2DZ $(\mathrm{d}, \mathrm{p})$ basis set. The vibrational wavenumbers of $\mathrm{C}_{4} \mathrm{H}_{4} \mathrm{Te}$ and $\mathrm{C}_{4} \mathrm{D}_{4} \mathrm{Te}$ were determined at the B3LYP/LANL2DZ(d,p) level under the harmonic approximation through analytical computations. Anharmonic terms were calculated numerically using the PT2 procedure implemented in the GAUSSIAN 09 program (option: Freq (VibRot, Anharmonic)) [20]. There are many reports in the literature confirming that the PT2 treatment in combination with DFT methods provides satisfactory performances, especially for computing anharmonic vibrational frequencies of cyclic structures [22-30]. In particular, the PT2 method and the B3LYP functional have been employed with success to obtain the vibrational spectra of the homologues furan [22, 25], thiophene [22], and more recently selenophene [30]. The used PT2 scheme computes the third and fourth energy derivatives with respect to the normal coordinates through a numerical differentiation procedure described in detail in [20]. The potential energy surface $(V)$ can be expanded including anharmonic contributions up to the quartic term as

$$
\begin{aligned}
\frac{V}{\mathrm{hc}}= & \frac{1}{2} \sum_{i} \omega_{i} q_{i}^{2}+\frac{1}{6} \sum_{i j k} \Phi_{i j k} q_{i} q_{j} q_{k} \\
& +\frac{1}{24} \sum_{i j k l} \Phi_{i j k l} q_{i} q_{j} q_{k} q_{l},
\end{aligned}
$$

where $\omega_{i}$ are the harmonic wavenumbers, $q_{i}$ are the dimensionless normal coordinates, $\Phi_{i j k}$ and $\Phi_{i j k l}$, are respectively, the third- and fourth-order force constants. The $\Phi_{i j k}$ and $\Phi_{i j k l}$ values are obtained through a finite difference scheme using quadratic normal coordinate force constants $\left(\Phi_{i j}\right)$ calculated analytically and performing displacements along each normal coordinate $\left(\delta_{q_{i}}\right)$ :

$$
\begin{gathered}
\Phi_{i j k}=\frac{1}{3}\left[\frac{\Phi_{j k}\left(+\delta q_{i}\right)-\Phi_{j k}\left(-\delta q_{i}\right)}{2 \delta q_{i}}+\frac{\Phi_{k i}\left(+\delta q_{j}\right)-\Phi_{k i}\left(-\delta q_{j}\right)}{2 \delta q_{j}}\right. \\
\left.+\frac{\Phi_{i j}\left(+\delta q_{k}\right)-\Phi_{i j}\left(-\delta q_{k}\right)}{2 \delta q_{k}}\right], \\
\Phi_{i j k k}=\frac{\Phi_{i j}\left(+\delta q_{k}\right)+\Phi_{i j}\left(-\delta q_{k}\right)-2 \Phi_{i j}(0)}{\delta q_{k}^{2}}, \\
\Phi_{i i k k}=\frac{1}{2}\left[\frac{\Phi_{i i}\left(+\delta q_{k}\right)+\Phi_{i i}\left(-\delta q_{k}\right)-2 \Phi_{i i}(0)}{\delta q_{k}^{2}}\right. \\
\left.+\frac{\Phi_{k k}\left(+\delta q_{i}\right)+\Phi_{k k}\left(-\delta q_{i}\right)-2 \Phi_{k k}(0)}{\delta q_{i}^{2}}\right] .
\end{gathered}
$$

As commonly adopted in the literature [24-26, 29, 30], step size displacements of $0.025 \AA$ along the normal coordinates were used in the present work. The fundamental frequencies $\left(v_{i}\right)$ were determined from the $\omega_{i}$, diagonal $\left(\chi_{i i}\right)$ and offdiagonal $\left(\chi_{i j}\right)$ anharmonic constants [20]:

$$
v_{i}=\omega_{i}+2 \chi_{i i}+\frac{1}{2} \sum_{j \neq i} \chi_{i j}
$$

\section{Result and Discussion}

Figure 1 displays the bond lengths and angles of $\mathrm{C}_{4} \mathrm{H}_{4} \mathrm{Te}$ calculated at the B3LYP/LANL2DZ(d,p) level. In addition, the figure reports the available experimental data obtained by microwave measurements [9]. The B3LYP/LANL2DZ(d,p) geometry is in good agreement with the observed one, especially for the bond lengths $\mathrm{C}-\mathrm{Te}$ (within $0.005 \AA$ ), $\mathrm{C}=\mathrm{C}$ (within $0.003 \AA$ ), and $\mathrm{C}-\mathrm{H}$ (the calculated and experimental values are identical), as well as for the bond angles (within $0.2-0.5^{\circ}$ ). Figure 1 also presents the vibrationally averaged geometries $\left(r_{z}\right.$ structure) calculated by the vibration-rotation interaction constant values [20]. In line with previous studies on cyclic compounds $[29,30]$, the vibrational averaging corrections lengthen the bond lengths of $\mathrm{C}_{4} \mathrm{H}_{4}$ Te by $0.001-$ $0.003 \AA$, whereas the bond angles vary within $0.2^{\circ}(\mathrm{C}-\mathrm{Te}-\mathrm{C})$.

The experimental infrared and Raman spectra of $\mathrm{C}_{4} \mathrm{H}_{4} \mathrm{Te}$ and $\mathrm{C}_{4} \mathrm{D}_{4}$ Te were obtained in vapour, liquid, $\mathrm{CCl}_{4}$ solution, and solid phase [10-14]. Theoretically, some calculations on the $\mathrm{C}_{4} \mathrm{H}_{4}$ Te isotopomer were previously performed using the harmonic treatment $[7,15]$. In Tables 1 and 2 we present the B3LYP/LANL2DZ(d,p) harmonic $(\omega)$ and anharmonic wavenumbers $(\nu)$, infrared intensities $\left(I_{\mathrm{IR}}\right)$ and Raman activities $\left(A_{\text {Raman }}\right)$ of $\mathrm{C}_{4} \mathrm{H}_{4} \mathrm{Te}$ and $\mathrm{C}_{4} \mathrm{D}_{4} \mathrm{Te}$, together with the available observed data for comparison [12]. The assignments of the vibrations were performed using normal modes as 
TABLE 1: Vibrational harmonic, $\omega$, and anharmonic, $v$, wavenumbers $\left(\mathrm{cm}^{-1}\right)$, infrared intensities, $I_{\mathrm{IR}}(\mathrm{km} / \mathrm{mol})$, and Raman activities $A_{\text {Raman }}$ $\left(\AA^{4} / \mathrm{amu}\right)$ of $\mathrm{C}_{4} \mathrm{H}_{4} \mathrm{Te}$.

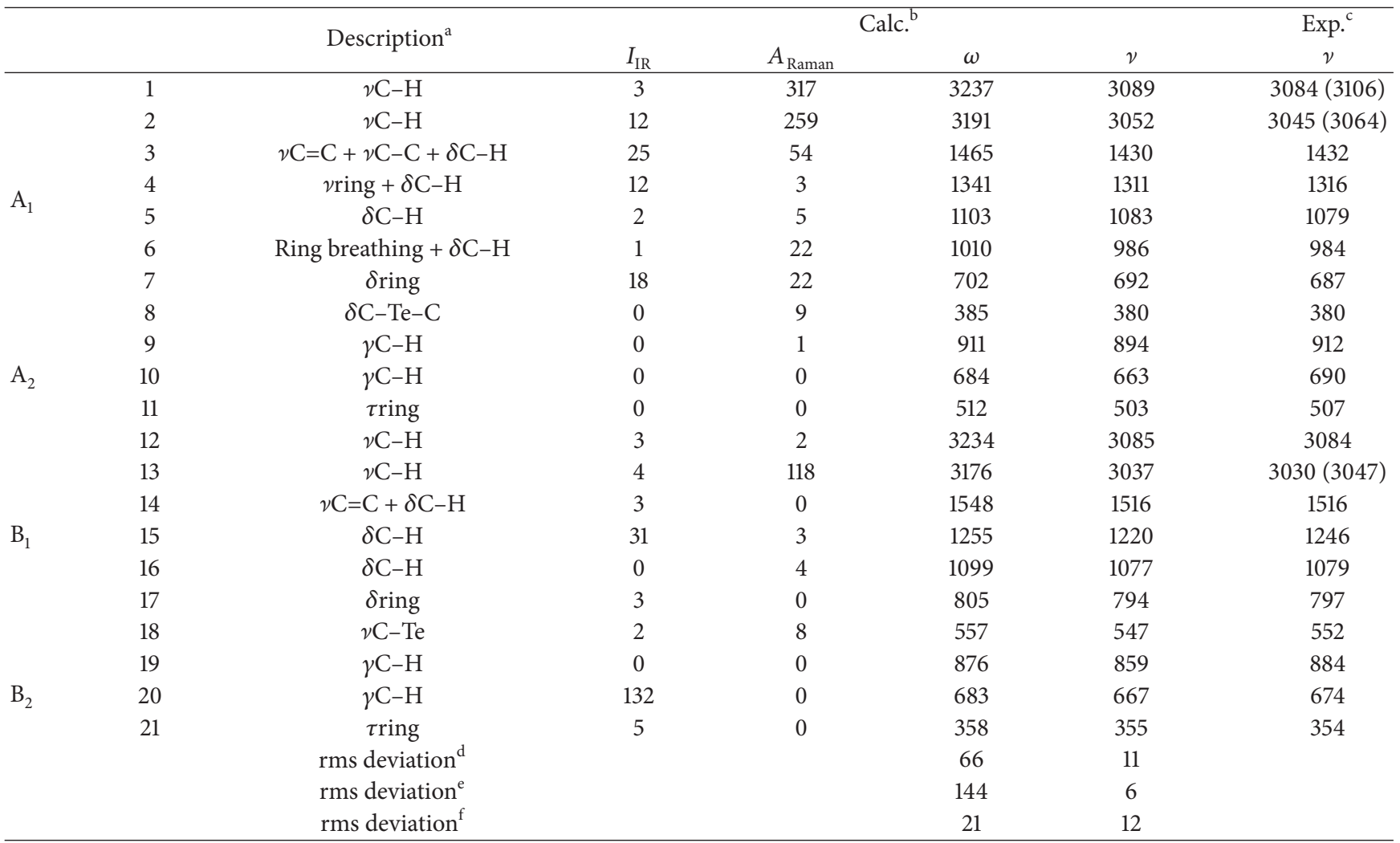

${ }^{\mathrm{a}} \nu$ : stretching; $\delta$ : in-plane bending; $\tau$ : torsion; $\gamma$ : out-of-plane bending.

${ }^{\mathrm{b}}$ Calculations were carried out in vacuum at the B3LYP/LANL2DZ(d,p) level.

${ }^{c}$ Liquid phase [12]. The values in parentheses refer to the gas phase [11].

${ }^{\mathrm{d}}$ All vibrational modes.

e $v \mathrm{C}-\mathrm{H}$ modes.

${ }^{\mathrm{f}}$ All vibrational modes excluding $\nu \mathrm{C}-\mathrm{H}$ modes.

displacements in redundant internal coordinates (in the GAUSSIAN 09, the option: Freq = IntModes) and also through the graphical program Chemcraft [36]. The title compounds belong to the $\mathrm{C}_{2 \mathrm{v}}$ symmetry point group with the 21 normal modes categorized as $8 \mathrm{~A}_{1}+3 \mathrm{~A}_{2}+7 \mathrm{~B}_{1}+3 \mathrm{~B}_{2}$. All the modes with the exception of the $A_{2}$ vibrations are infrared active. It is worth noting that, the current assignments of the transitions reasonably agree with those previously determined by experimental [12] and computational [7, 15] studies. The complete sets of experimental fundamentals of both the investigated isotopomers are available from measurements in liquid phase [12], whereas three $\mathrm{C}-\mathrm{H}$ stretching transitions (modes numbers 1, 2, and 13) of $\mathrm{C}_{4} \mathrm{H}_{4}$ Te were also detected in gas [11].

The harmonic frequencies systematically overestimate the experimental data with the notable exception of the modes numbers 9,10 , and 19 for $\mathrm{C}_{4} \mathrm{H}_{4}$ Te and of the modes numbers 10 and 19 for $\mathrm{C}_{4} \mathrm{D}_{4} \mathrm{Te}$. In the present study, we determined the root mean square (rms) deviation between the experimental and calculated wavenumbers which is defined as follows:

$$
\mathrm{rms}=\left[\frac{1}{n} \sum_{i}^{n}\left(v_{i}^{\text {exp }}-v_{i}^{\text {calc. }}\right)^{2}\right]^{1 / 2},
$$

where $v_{i}$ is a vibrational frequency value. The rms deviations are included in Tables 1 and 2 for all the modes, the C$\mathrm{H} / \mathrm{C}-\mathrm{D}$ stretching vibrations $(\nu \mathrm{C}-\mathrm{H} / \nu \mathrm{C}-\mathrm{D})$, and all the modes except for the $\nu \mathrm{C}-\mathrm{H}$ and $\nu \mathrm{C}-\mathrm{D}$ vibrations. When considering all the vibrational transitions, the rms deviations between the harmonic and observed data are $66 \mathrm{~cm}^{-1}$ for $\mathrm{C}_{4} \mathrm{H}_{4}$ Te and $43 \mathrm{~cm}^{-1}$ for $\mathrm{C}_{4} \mathrm{D}_{4} \mathrm{Te}$. These rms deviations are noticeably reduced if we exclude the $\nu \mathrm{C}-\mathrm{H}$ and $\nu \mathrm{C}-\mathrm{D}$ modes, becoming $21 \mathrm{~cm}^{-1}$ and $18 \mathrm{~cm}^{-1}$, respectively. On the whole, the modification of the basis set for the $\mathrm{C}$ and $\mathrm{H}$ atoms [LANL2DZ $(d, p) \rightarrow 6-311 G(d, p)]$ does not produce significant effects on the harmonic wavenumber values of $\mathrm{C}_{4} \mathrm{H}_{4} \mathrm{Te}$ (the data are available on request from the author), giving a rms deviation of $63 \mathrm{~cm}^{-1}$ with respect to the experimental data. Specifically, the performances of the 6-311G $(\mathrm{d}, \mathrm{p})$ in comparison to the LANL2DZ(d,p) basis set are slightly improved for the $\mathrm{C}-\mathrm{H}$ stretches ( $\mathrm{rms}$ deviation of 135 versus $144 \mathrm{~cm}^{-1}$ ), but worsened for the remaining modes (rms deviation of 23 versus $21 \mathrm{~cm}^{-1}$ ). Therefore, for the anharmonic computations the use of the smaller LANL2DZ(d,p) basis set for all the atoms can be considered a reasonable choice. Although the experimental wavenumber values of the 21 fundamentals were obtained in liquid phase [12] and the present 
TABLE 2: Vibrational harmonic, $\omega$, and anharmonic, $v$, frequencies $\left(\mathrm{cm}^{-1}\right)$, infrared intensities, $I_{\mathrm{IR}}(\mathrm{km} / \mathrm{mol})$, and Raman activities $A_{\text {Raman }}$ $\left(\AA^{4} / \mathrm{amu}\right)$ of $\mathrm{C}_{4} \mathrm{D}_{4} \mathrm{Te}$.

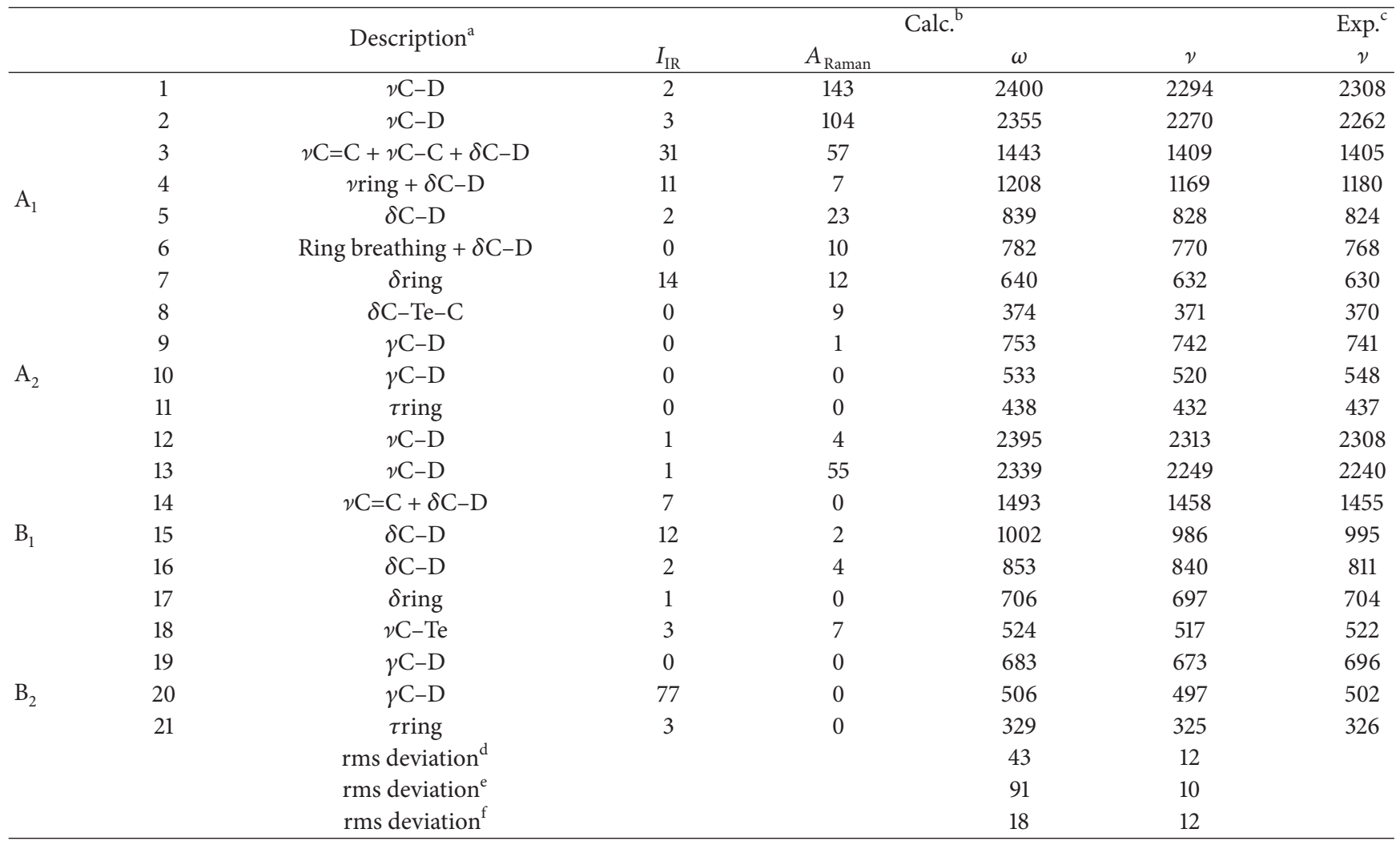

${ }^{\mathrm{a}} \nu$ : stretching; $\delta$ : in-plane bending; $\tau$ : torsion; $\gamma$ : out-of-plane bending.

${ }^{\mathrm{b}}$ Calculations were carried out in vacuum at the B3LYP/LANL2DZ(d,p) level.

${ }^{\mathrm{c}}$ Liquid phase [12].

${ }^{\mathrm{d}}$ All vibrational modes.

e $v$ C-H modes.

${ }^{\mathrm{f}}$ All vibrational modes excluding $\nu \mathrm{C}-\mathrm{H}$ modes.

calculations were performed in vacuum, the introduction of the PT2 anharmonic corrections generally improves the agreement between the observed and computed data; for all the vibrational transitions the rms deviations are $11 \mathrm{~cm}^{-1}$ for $\mathrm{C}_{4} \mathrm{H}_{4} \mathrm{Te}$ and $12 \mathrm{~cm}^{-1}$ for $\mathrm{C}_{4} \mathrm{D}_{4} \mathrm{Te}$. As should be expected, the calculated harmonic wavenumbers overestimate the anharmonic figures, the zero-point energy (ZPE) correction, a physicochemical property of fundamental importance for an accurate determination of thermochemical and kinetic parameters, being influenced by the anharmonic corrections. Indeed, when passing from the harmonic to the PT2 anharmonic treatment, the $\mathrm{ZPE}$ for $\mathrm{C}_{4} \mathrm{H}_{4} \mathrm{Te}\left(\mathrm{C}_{4} \mathrm{D}_{4} \mathrm{Te}\right)$ decreases from $40.22(32.30)$ to $39.72(31.44) \mathrm{kcal} / \mathrm{mol}$.

As can be appreciated from the data reported in Tables 1 and 2, the largest anharmonic contributions are found for the $\nu \mathrm{C}-\mathrm{H}$ and $\nu \mathrm{C}-\mathrm{D}$ transitions (modes. numbers $1,2,12$, and 13), decreasing the harmonic frequency values of $\mathrm{C}_{4} \mathrm{H}_{4} \mathrm{Te}$ by $140-150 \mathrm{~cm}^{-1}$ (ca. $4 \%$ ) and of $\mathrm{C}_{4} \mathrm{D}_{4} \mathrm{Te} 80-110 \mathrm{~cm}^{-1}$ (ca. 3$4 \%$ ), in agreement with previous PT2 computations on other cyclic compounds [22-30]. As a consequence, the agreement between the experimental and calculated wavenumbers for the $\nu \mathrm{C}-\mathrm{H}$ and $\nu \mathrm{C}-\mathrm{D}$ stretches is significantly improved by the anharmonic treatment (within $1-14 \mathrm{~cm}^{-1}, 0.03-0.61 \%$ ). Note that when we consider the gas phase experimental $\nu \mathrm{C}-$ $\mathrm{H}$ fundamentals of $\mathrm{C}_{4} \mathrm{H}_{4} \mathrm{Te}$ (modes numbers 1,2 , and 13 , Table 1), the experimental/calculation deviations are slightly augmented (up to $17 \mathrm{~cm}^{-1}$ ). To elucidate the origin of the above large anharmonic effects, as a case test, we analysed the contributions of the anharmonic constant values $\left(\chi_{i, j}\right)$ for the $\nu \mathrm{C}-\mathrm{H}$ modes numbers 1 and 2 of $\mathrm{C}_{4} \mathrm{H}_{4} \mathrm{Te}$ (Figure 2). The most significant $\chi_{i, j}$ corrections are produced by the diagonal term $\left(\chi_{i, i}\right)$ as well as by the coupling with the remaining $\mathrm{C}-\mathrm{H}$ stretching modes. In the specific case of the modes numbers 1 and 2, the largest anharmonic coupling are $\chi_{1,12}$ and $\chi_{2,13}$, which are predicted to be ca. $-120 \mathrm{~cm}^{-1}$ and recover about $80 \%$ of the total anharmonic corrections $(\omega-\nu,(3))$. Other nonnegligible anharmonic contributions, although less substantial than $\chi_{1,12}$ and $\chi_{2,13}$, are given by the $\chi_{1,1}, \chi_{2,2}$ (ca. $-30 \mathrm{~cm}^{-1}$ for both the couplings), and $\chi_{1,2}\left(-12 \mathrm{~cm}^{-1}\right)$ terms.

For the $\nu \mathrm{C}-\mathrm{H} / \nu \mathrm{C}-\mathrm{D}$ modes, we evaluated the $\mathrm{H} \rightarrow \mathrm{D}$ isotopic wavenumber downward shifts $\left(\Delta \nu_{\mathrm{H} / \mathrm{D}}=\nu \mathrm{C}-\mathrm{H}-\nu \mathrm{C}-\mathrm{D}\right)$ obtained by the harmonic and anharmonic calculations. The deviations of the calculated $\Delta \nu_{\mathrm{H} / \mathrm{D}}$ data from the observed values are reported in Figure 3, together with the percentage 
TABLE 3: Wavenumbers of first overtones $\left(\mathrm{cm}^{-1}\right)$ of tellurophene isotopomers.

\begin{tabular}{|c|c|c|c|c|c|c|c|}
\hline \multirow{3}{*}{ Symm. } & \multirow{3}{*}{ Mode no. ${ }^{\text {a }}$} & \multicolumn{3}{|c|}{$\mathrm{C}_{4} \mathrm{H}_{4} \mathrm{Te}$} & \multicolumn{3}{|c|}{$\mathrm{C}_{4} \mathrm{D}_{4} \mathrm{Te}$} \\
\hline & & \multicolumn{2}{|c|}{ Calc. } & \multirow{2}{*}{$\begin{array}{c}\text { Exp. }^{\mathrm{c}} \\
v\end{array}$} & \multicolumn{2}{|c|}{ Calc. $^{\mathrm{b}}$} & \multirow{2}{*}{$\begin{array}{c}\text { Exp. } \\
v\end{array}$} \\
\hline & & $\omega$ & $v$ & & $\omega$ & $v$ & \\
\hline \multirow{8}{*}{$\mathrm{A}_{1}$} & 1 & 6474 & 6144 & & 4801 & 4575 & \\
\hline & 2 & 6382 & 6047 & & 4711 & 4516 & \\
\hline & 3 & 2931 & 2848 & 2851 & 2886 & 2810 & \\
\hline & 4 & 2683 & 2617 & 2627 & 2415 & 2343 & \\
\hline & 5 & 2205 & 2167 & 2160 & 1678 & 1652 & \\
\hline & 6 & 2019 & 1968 & 1966 & 1563 & 1541 & \\
\hline & 7 & 1404 & 1382 & & 1279 & 1263 & 1254 \\
\hline & 8 & 769 & 759 & 758 & 748 & 740 & \\
\hline \multirow{3}{*}{$\mathrm{A}_{2}$} & 9 & 1823 & 1788 & 1822 & 1505 & 1485 & \\
\hline & 10 & 1369 & 1322 & 1385 & 1067 & 1039 & \\
\hline & 11 & 1024 & 1009 & 1014 & 877 & 864 & 872 \\
\hline \multirow{7}{*}{$\mathrm{B}_{1}$} & 12 & 6469 & 6083 & & 4789 & 4598 & \\
\hline & 13 & 6351 & 6013 & & 4679 & 4478 & \\
\hline & 14 & 3096 & 3019 & 3015 & 2986 & 2921 & 2916 \\
\hline & 15 & 2510 & 2451 & & 2004 & 1969 & \\
\hline & 16 & 2199 & 2154 & & 1706 & 1680 & \\
\hline & 17 & 1611 & 1588 & & 1412 & 1393 & \\
\hline & 18 & 1114 & 1093 & 1111 & 1049 & 1031 & 1049 \\
\hline \multirow{3}{*}{$\mathrm{B}_{2}$} & 19 & 1753 & 1717 & 1768 & 1367 & 1347 & 1383 \\
\hline & 20 & 1367 & 1331 & & 1013 & 993 & \\
\hline & 21 & 716 & 709 & & 657 & 650 & \\
\hline
\end{tabular}

${ }^{\mathrm{a}}$ See Tables 1 and 2 for the mode description.

${ }^{\mathrm{b}}$ Calculations were carried out in vacuum at the B3LYP/LANL2DZ(d,p) level.

${ }^{\mathrm{c}}$ Liquid phase, [12].

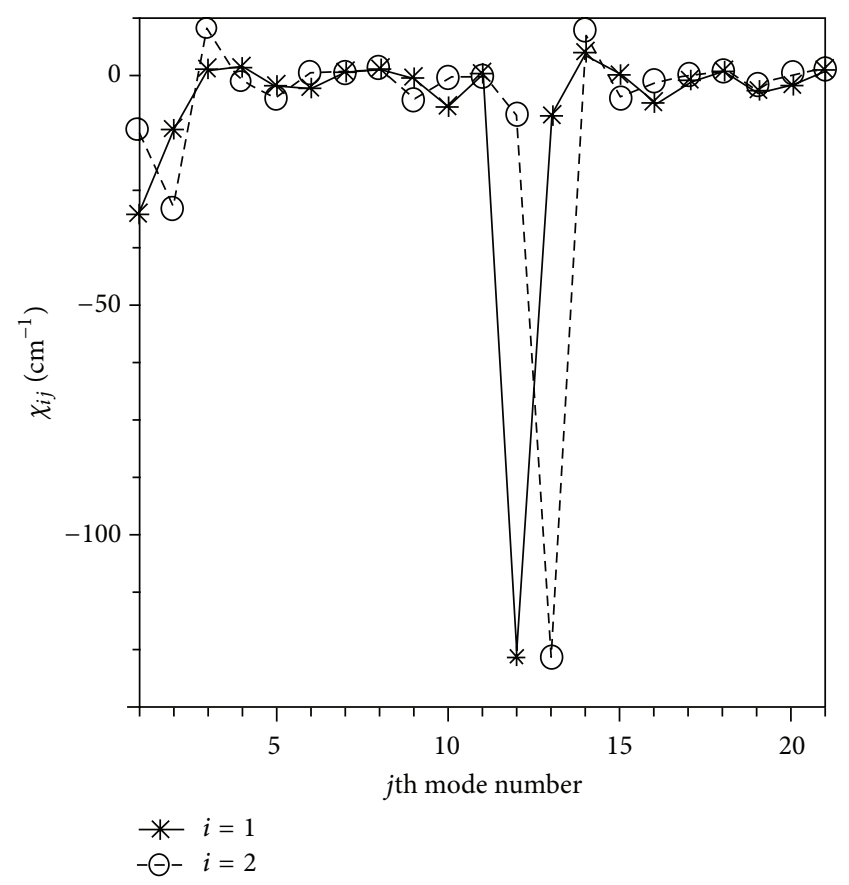

FIGURE 2: B3LYP/LANL2DZ(d,p) anharmonic vibrational constants for the $\mathrm{C}-\mathrm{H}$ stretching modes numbers 1 and 2 with the vibrational modes $j=1-21$ of $\mathrm{C}_{4} \mathrm{H}_{4}$ Te. For the mode numbering, see Table 1 . errors. The harmonic approximation overestimates the experimental shifts by $47-63 \mathrm{~cm}^{-1}(5.9-8.1 \%)$, whereas the anharmonic computations, with the exception of mode number 1 , underestimate the isotopic shifts showing smaller errors (1$19 \mathrm{~cm}^{-1}, 0.1-2.4 \%$ ). The results are particularly excellent for the mode number 2 .

Table 3 collects the frequencies of the overtone bands of title compounds obtained using the harmonic and anharmonic approaches, together with the available experimental data which are only limited to eleven $\left(\mathrm{C}_{4} \mathrm{H}_{4} \mathrm{Te}\right)$ and five $\left(\mathrm{C}_{4} \mathrm{D}_{4} \mathrm{Te}\right)$ vibrational modes. Confirming the above results of the fundamentals, the greatest anharmonic corrections for the overtones occur for the $\nu \mathrm{C}-\mathrm{H}(\nu \mathrm{C}-\mathrm{D})$ transitions, which reduce the harmonic values by ca. 5-6\% (4-5\%).

In Figures 4 and 5 we plot the infrared and Raman spectra obtained by the anharmonic calculations using pure Lorentzian band-shapes with a full width at half maximum of $10 \mathrm{~cm}^{-1}$. The $\mathrm{C}-\mathrm{H}$ and $\mathrm{C}-\mathrm{D}$ stretching transitions are placed in the highest-wavenumber regions of the vibrations spectra. The lowest-energy region of the infrared spectra of $\mathrm{C}_{4} \mathrm{H}_{4} \mathrm{Te}$ and $\mathrm{C}_{4} \mathrm{D}_{4}$ Te is mainly characterized by an isolated and strong absorption located at $667 \mathrm{~cm}^{-1}\left(I_{\mathrm{IR}}=132 \mathrm{~km} / \mathrm{mol}\right)$ and $497 \mathrm{~cm}^{-1}\left(I_{\mathrm{IR}}=77 \mathrm{~km} / \mathrm{mol}\right)$, respectively, to be compared with the experimental values of $674 \mathrm{~cm}^{-1}(-1 \%)$ and $502 \mathrm{~cm}^{-1}$ $(-1 \%)$, respectively. The vibrational analysis ascribes this 


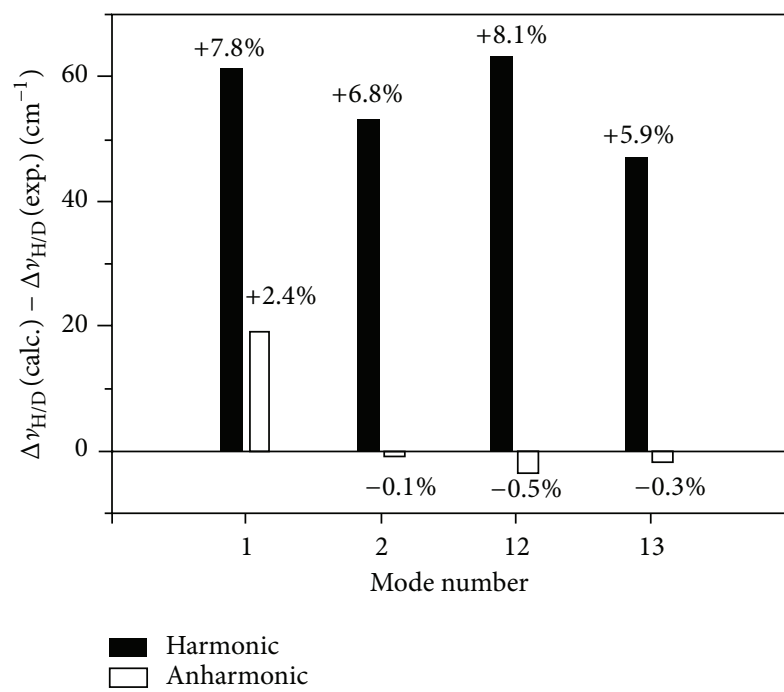

Figure 3: Deviation of the B3LYP/LANL2DZ(d,p) $\mathrm{H} \rightarrow \mathrm{D}$ isotopic wavenumber shifts $\left(\Delta \nu_{\mathrm{H} / \mathrm{D}}\right)$ for the $\mathrm{C}-\mathrm{H}$ and $\mathrm{C}-\mathrm{D}$ stretching modes from experiment [12]. The reported values refer to the percentage deviations.

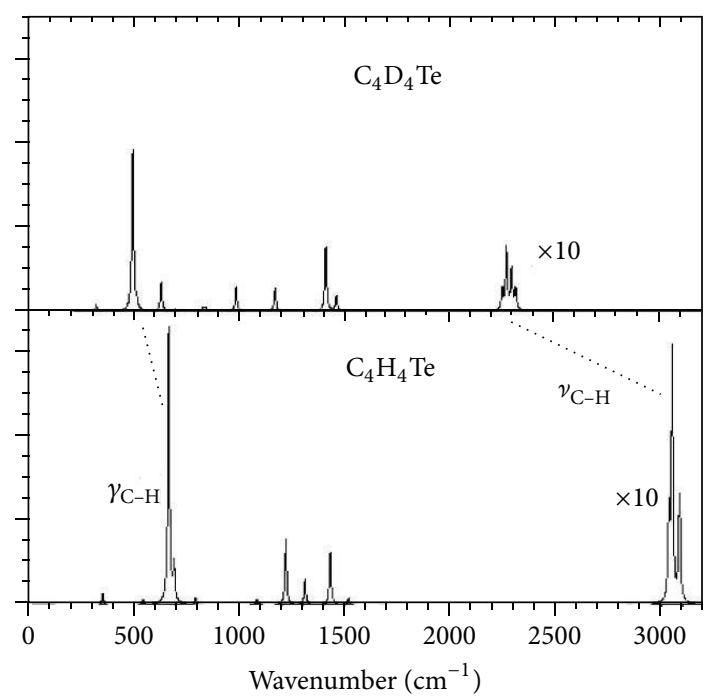

Figure 4: Anharmonic infrared spectra of $\mathrm{C}_{4} \mathrm{H}_{4} \mathrm{Te}$ (bottom) and $\mathrm{C}_{4} \mathrm{D}_{4} \mathrm{Te}$ (top). Lorentz line-shapes with half-width of $10 \mathrm{~cm}^{-1}$ are used. B3LYP/LANL2DZ(d,p) results.

transition (mode number 20) to a pure out-of-plane $\mathrm{C}-\mathrm{H}$ (and C-D) bending deformation, $\gamma \mathrm{C}-\mathrm{H}(\gamma \mathrm{C}-\mathrm{D})$. A graphical representation of the atomic displacement vectors involved in this vibration is depicted in Figure 6(a).

The most active transitions in the Raman spectra of $\mathrm{C}_{4} \mathrm{H}_{4} \mathrm{Te}$ and $\mathrm{C}_{4} \mathrm{D}_{4} \mathrm{Te}$ involve the $\mathrm{C}-\mathrm{H}$ and $\mathrm{C}-\mathrm{D}$ stretches (Tables 1 and 2). From the present calculations, an almost isolated and relatively intense peak $\left(A_{\text {Raman }} \sim 50 \AA^{4} / \mathrm{amu}\right)$ located near $1400 \mathrm{~cm}^{-1}$ appears in the Raman spectra of both tellurophene and its perdeuterated isotopomer. This transition (mode number 3) also visible in the infrared spectra is assigned to the $\mathrm{C}=\mathrm{C}+\mathrm{C}-\mathrm{C}$ bonds stretchings with

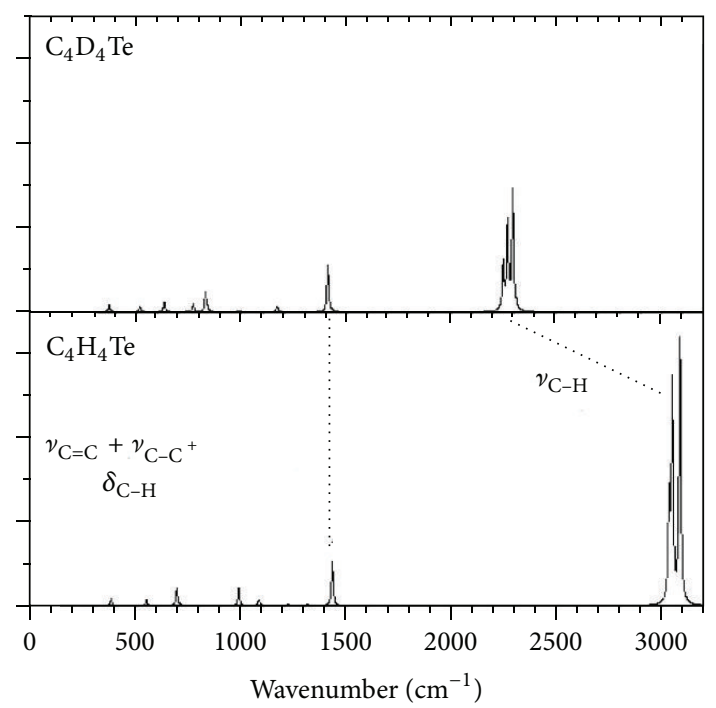

FIgure 5: Anharmonic Raman spectra of $\mathrm{C}_{4} \mathrm{H}_{4}$ Te (bottom) and $\mathrm{C}_{4} \mathrm{D}_{4} \mathrm{Te}$ (top). Lorentz line-shapes with half-width of $10 \mathrm{~cm}^{-1}$ are used. B3LYP/LANL2DZ(d,p) results.

the nonnegligible contribution from the in-plane C-H (C-D) bending motion (Figure 6(b)). The present harmonic computations place this band at $1465 \mathrm{~cm}^{-1}\left(\mathrm{C}_{4} \mathrm{H}_{4} \mathrm{Te}\right)$ and $1443 \mathrm{~cm}^{-1}$ $\left(\mathrm{C}_{4} \mathrm{D}_{4} \mathrm{Te}\right)$, overestimating the observed wavenumbers of $1432 \mathrm{~cm}^{-1}(+2.3 \%)$ and $1405 \mathrm{~cm}^{-1}(+2.7 \%)$, respectively. Note that the corresponding PT2 anharmonic frequencies here calculated at $1430 \mathrm{~cm}^{-1}\left(\mathrm{C}_{4} \mathrm{H}_{4} \mathrm{Te}\right)$ and $1409 \mathrm{~cm}^{-1}\left(\mathrm{C}_{4} \mathrm{D}_{4} \mathrm{Te}\right)$, give a noticeably better agreement with experiment (within $0.1-0.3 \%)$.

\section{Conclusions}

In this work we computed harmonic and PT2 anharmonic vibrational frequencies of fundamentals and overtone bands of $\mathrm{C}_{4} \mathrm{H}_{4} \mathrm{Te}$ and $\mathrm{C}_{4} \mathrm{D}_{4} \mathrm{Te}$. The computations were performed in vacuum at the B3LYP/LANL2DZ(d,p) level of theory. The infrared and Raman spectral profiles were simulated using Lorentzian band-shapes and the most informative transitions were discussed. In general, the calculated harmonic frequencies deviate from the observed ones, with $\mathrm{rms}$ deviations of 66 and $43 \mathrm{~cm}^{-1}$ for $\mathrm{C}_{4} \mathrm{H}_{4} \mathrm{Te}$ and $\mathrm{C}_{4} \mathrm{D}_{4} \mathrm{Te}$, respectively. The introduction of the PT2 anharmonic contributions in several cases significantly reduces the calculation/experiment discrepancy, giving rms deviations of $11 \mathrm{~cm}^{-1}\left(\mathrm{C}_{4} \mathrm{H}_{4} \mathrm{Te}\right)$ and $12 \mathrm{~cm}^{-1}\left(\mathrm{C}_{4} \mathrm{D}_{4} \mathrm{Te}\right)$. A vibrational analysis reveals that the anharmonic corrections are especially conspicuous for the $\nu \mathrm{C}-\mathrm{H}$ and $\nu \mathrm{C}-\mathrm{D}$ transitions, decreasing the harmonic wavenumber values, respectively, by $140-150 \mathrm{~cm}^{-1}$ (ca. $4 \%$ ) and $80-110 \mathrm{~cm}^{-1}$ (ca. $3-4 \%$ ), and noticeably improving the agreement with the experimental data. As a consequence, in comparison to the harmonic approximation, the observed $\mathrm{H} \rightarrow \mathrm{D}$ isotopic frequency red-shifts for the $\mathrm{C}-\mathrm{H}$ and $\mathrm{C}-$ $\mathrm{D}$ stretches are better reproduced by the PT2 scheme with deviation up to $1-19 \mathrm{~cm}^{-1}(0.1-2.4 \%)$. Important anharmonic effects (ca. $35 \mathrm{~cm}^{-1}, 2.3 \%$ ) are also found for the mode 


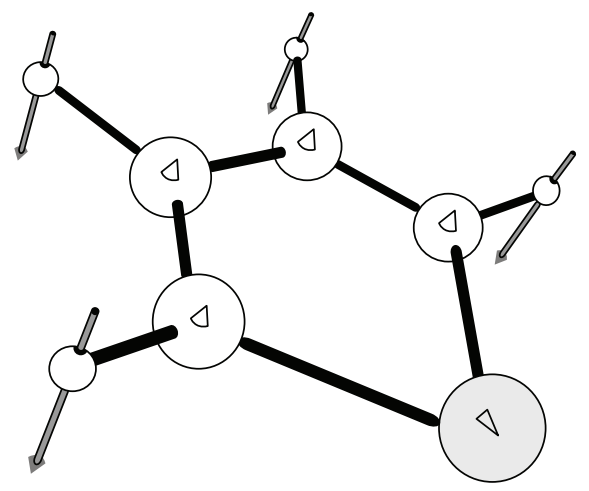

(a)

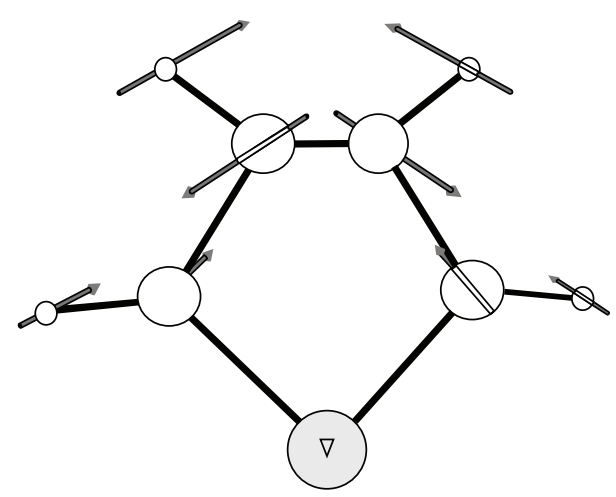

(b)

FIGURE 6: Atom vector displacements for the normal modes of $\mathrm{C}_{4} \mathrm{H}_{4}$ Te: (a) $\gamma \mathrm{C}-\mathrm{H}$ (mode number 20 ); (b) $\nu \mathrm{C}=\mathrm{C}+\nu \mathrm{C}-\mathrm{C}+\delta \mathrm{C}-\mathrm{H}$ (mode number 3). B3LYP/LANL2DZ(d,p) results.

number $3(\nu \mathrm{C}=\mathrm{C}+\nu \mathrm{C}-\mathrm{C}+\delta \mathrm{C}-\mathrm{H}, \nu \mathrm{C}=\mathrm{C}+\nu \mathrm{C}-\mathrm{C}+\delta \mathrm{C}-$ $\mathrm{D})$, characterized by a relatively intense peak in the Raman spectra. In line with the recent literature, the present results on tellurophene isotopomers confirm that the anharmonic PT2-DFT approach can be employed to accurately predict the infrared and Raman spectra of heterocyclic compounds.

\section{Conflict of Interests}

The author declares that there is no conflict of interests regarding the publication of this paper.

\section{References}

[1] S. Inoue, T. Jigami, H. Nozoe, T. Otsubo, and F. Ogura, "2,2' -Bitellurophene and $2,2^{\prime}: 5^{\prime}, 2^{\prime \prime}$-tertellurophene as novel high homologues of tellurophene," Tetrahedron Letters, vol. 35, no. 43, pp. 8009-8012, 1994

[2] Q. Lei, X. H. Yin, K. Kobayashi, T. Kawai, M. Ozaki, and K. Yoshino, "Electrical properties of polymer composties: conducting polymer-polyacene quinone radical polymer," Synthetic Metals, vol. 69, no. 1-3, pp. 357-358, 1995.

[3] S. Millefiori and A. Alparone, "(Hyper)polarizability of chalcogenophenes $\mathrm{C}_{4} \mathrm{H}_{4} \mathrm{X}(\mathrm{X}=\mathrm{O}, \mathrm{S}, \mathrm{Se}, \mathrm{Te})$ conventional ab initio and density functional theory study," Journal of Molecular Structure: THEOCHEM, vol. 431, no. 1-2, pp. 59-78, 1998.
[4] K. Kamada, T. Sugino, M. Ueda, K. Tawa, Y. Shimizu, and K. Ohta, "Femtosecond optical Kerr study of heavy-atom effects on the third-order optical non-linearity of thiophene homologues: electronic hyperpolarizability of tellurophene," Chemical Physics Letters, vol. 302, no. 5-6, pp. 615-620, 1999.

[5] S. Millefiori and A. Alparone, "Second hyperpolarisability of furan homologues $\mathrm{C}_{4} \mathrm{H}_{4} \mathrm{X}(\mathrm{X}=\mathrm{O}, \mathrm{S}, \mathrm{Se}, \mathrm{Te})$ : $\mathrm{Ab}$ initio $\mathrm{HF}$ and DFT study," Chemical Physics Letters, vol. 332, no. 1-2, pp. 175$180,2000$.

[6] K. Kamada, M. Ueda, H. Nagao et al., "Molecular design for organic nonlinear optics: polarizability and hyperpolarizabilities of furan homologues investigated by ab initio molecular orbital method," Journal of Physical Chemistry A, vol. 104, no. 20, pp. 4723-4734, 2000.

[7] S. Millefiori and A. Alparone, "Theoretical determination of the vibrational and electronic (hyper)polarizabilities of $\mathrm{C}_{4} \mathrm{H}_{4} \mathrm{X}(\mathrm{X}=$ $\mathrm{O}, \mathrm{S}, \mathrm{Se}, \mathrm{Te}$ ) heterocycles," Physical Chemistry Chemical Physics, vol. 2, no. 11, pp. 2495-2501, 2000.

[8] B. Jansik, B. Schimmelpfennig, P. Norman, P. Macak, H. Ågren, and K. Ohta, "Relativistic effects on linear and non-linear polarizabilities of the furan homologues," Journal of Molecular Structure: THEOCHEM, vol. 633, no. 2-3, pp. 237-246, 2003.

[9] V. K. Yadav, A. Yadav, and R. A. Poirier, "Some periodic trends in organic compounds containing $\mathrm{O}, \mathrm{S}, \mathrm{Se}$, and Te: an ab initio study," Journal of Molecular Structure: THEOCHEM, vol. 186, no. C, pp. 101-116, 1989.

[10] A. Poletti, R. Cataliotti, and G. Paliani, "Infrared crystal spectra of heterocyclic compounds. II. IR spectrum of selenophene in the solid state," Chemical Physics, vol. 5, no. 2, pp. 291-297, 1974.

[11] R. Cataliotti and G. Paliani, "Infrared study of the C-H stretching region of five-membered heterocyclic compounds," Canadian Journal of Chemistry, vol. 54, pp. 2451-2457, 1976.

[12] G. Paliani, R. Cataliotti, A. Poletti, F. Fringuelli, A. Taticchi, and M. G. Giorgini, "Vibrational analysis of tellurophene and its deuterated derivatives," Spectrochimica Acta Part A, vol. 32, no. 5, pp. 1089-1104, 1976.

[13] A. Santucci, G. Paliani, and R. S. Cataliotti, "Force field calculation of the in-plane fundamental motions of tellurophene and selenophene," Spectrochimica Acta Part A, vol. 41, no. 5, pp. 679685, 1985.

[14] A. Santucci, G. Paliani, and R. S. Cataliotti, "Force field calculation of the out-of-plane fundamental modes of tellurophene and selenophene," Chemical Physics Letters, vol. 138, no. 2-3, pp. 244-249, 1987.

[15] A. A. El-Azhary and A. A. Al-Kahtani, "Force field scale factors of effective core potential basis sets of some selenium and tellurium heterocyclic molecules, selenophene, 1,2,5-selenadiazole, tellurophene and 1,2,5-telluradiazole," Journal of Molecular Structure: THEOCHEM, vol. 572, pp. 81-87, 2001.

[16] W. J. Hehre, L. Random, P. V. R. Schleyer, and J. A. Pople, Ab Initio Molecular Orbital Theory, Wiley, New York, NY, USA, 1986.

[17] P. Pulay, G. Fogarasi, G. Pongor, J. E. Boggs, and A. Vargha, "Combination of theoretical ab initio and experimental information to obtain reliable harmonic force constants. Scaled quantum mechanical (SQM) force fields for glyoxal, acrolein, butadiene, formaldehyde, and ethylene," Journal of the American Chemical Society, vol. 105, no. 24, pp. 7037-7047, 1983.

[18] G. Rauhut and P. Pulay, "Transferable scaling factors for density functional derived vibrational force fields," Journal of Physical Chemistry, vol. 99, no. 10, pp. 3093-3100, 1995. 
[19] J. M. Bowman, "Self-consistent field energies and wavefunctions for coupled oscillators," The Journal of Chemical Physics, vol. 68 , no. 2, pp. 608-610, 1978.

[20] V. Barone, "Anharmonic vibrational properties by a fully automated second-order perturbative approach," Journal of Chemical Physics, vol. 122, no. 1, Article ID 014108, 2005.

[21] D. A. Clabo Jr., W. D. Allen, R. B. Remington, Y. Yamaguchi, and H. F. Schaefer III, "A systematic study of molecular vibrational anharmonicity and vibration-rotation interaction by selfconsistent-field higher-derivative methods. Asymmetric top molecules," Chemical Physics, vol. 123, no. 2, pp. 187-239, 1988.

[22] R. Burcl, N. C. Handy, and S. Carter, "Vibrational spectra of furan, pyrrole, and thiophene from a density functional theory anharmonic force field," Spectrochimica Acta Part A, vol. 59, no. 8, pp. 1881-1893, 2003.

[23] N. C. Handy and A. Willetts, "Anharmonic constants for benzene," Spectrochimica Acta Part A, vol. 53, no. 8, pp. 1169-1177, 1997.

[24] V. Barone, "Accurate vibrational spectra of large molecules by density functional computations beyond the harmonic approximation: the case of azabenzenes," Journal of Physical Chemistry A, vol. 108, no. 18, pp. 4146-4150, 2004.

[25] V. Barone, "Vibrational spectra of large molecules by density functional computations beyond the harmonic approximation: the case of pyrrole and furan," Chemical Physics Letters, vol. 383, no. 5-6, pp. 528-532, 2004.

[26] V. Barone, G. Festa, A. Grandi, N. Rega, and N. Sanna, "Accurate vibrational spectra of large molecules by density functional computations beyond the harmonic approximation: the case of uracil and 2-thiouracil," Chemical Physics Letters, vol. 388, no. 4-6, pp. 279-283, 2004.

[27] A. D. Boese and J. M. L. Martin, "Vibrational spectra of the azabenzenes revisited: anharmonic force fields," Journal of Physical Chemistry A, vol. 108, no. 15, pp. 3085-3096, 2004.

[28] V. Librando, A. Alparone, and Z. Minniti, "Computational note on anharmonic infrared spectrum of naphthalene," Journal of Molecular Structure: THEOCHEM, vol. 847, no. 1-3, pp. 23-24, 2007.

[29] A. Alparone, "Ab initio and DFT anharmonic spectroscopic investigation of 1,3-cyclopentadiene," Chemical Physics, vol. 327, pp. 127-136, 2006.

[30] A. Alparone, "Infrared and Raman spectra of $\mathrm{C}_{4} \mathrm{H}_{4} \mathrm{Se}$ and $\mathrm{C}_{4} \mathrm{D}_{4}$ Se isotopomers: a DFT-PT2 anharmonic study," Journal of Chemistry, vol. 2013, Article ID 741472, 8 pages, 2013.

[31] A. D. Becke, "A new mixing of Hartree-Fock and local densityfunctional theories," The Journal of Chemical Physics, vol. 98, no. 2, pp. 1372-1377, 1993.

[32] C. Lee, W. Yang, and R. G. Parr, "Development of the ColleSalvetti correlation-energy formula into a functional of the electron density," Physical Review B, vol. 37, no. 2, pp. 785-789, 1988.

[33] T. H. Dunning Jr. and P. J. Hay, in Modern Theoretical Chemistry, H. F. Schaefer III, Ed., vol. 3, pp. 1-28, Plenum, New York, NY, USA, 1976.

[34] W. R. Wadt and P. J. Hay, "Ab initio effective core potentials for molecular calculations. Potentials for main group elements $\mathrm{Na}$ to Bi," The Journal of Chemical Physics, vol. 82, no. 1, pp. 284298, 1985.

[35] M. J. Frisch, G. W. Trucks, H. B. Schlegel et al., GAUSSIAN 09, Revision A.02, Gaussian, Inc., Wallingford, Conn, USA, 2009.

[36] G. A. Zhurko and D. A. Zhurko, "Chemcraft," http://www.chemcraftprog.com/. 

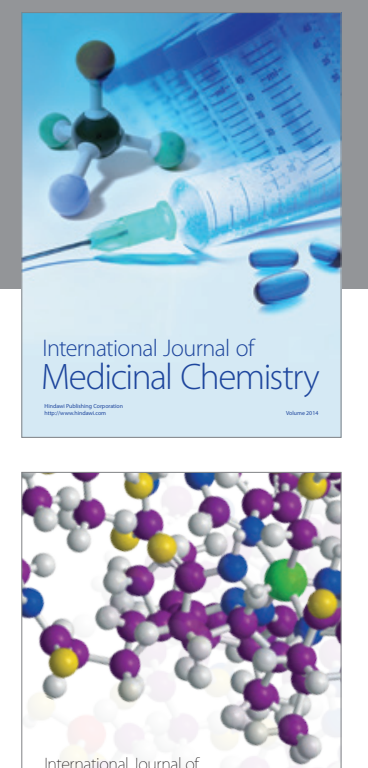

\section{Carbohydrate} Chemistry

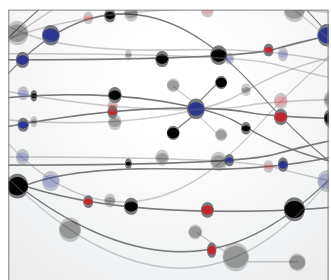

The Scientific World Journal
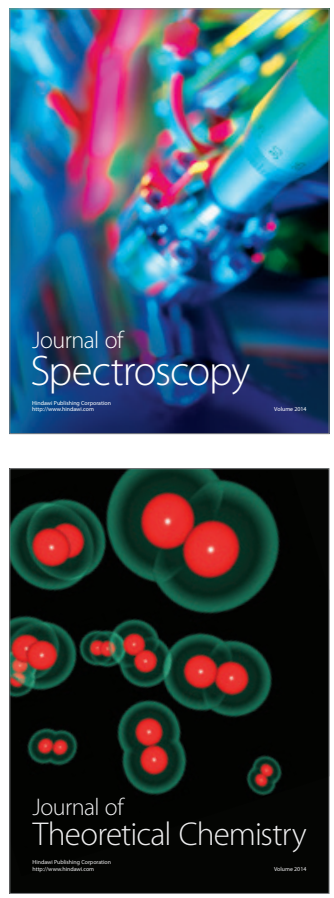
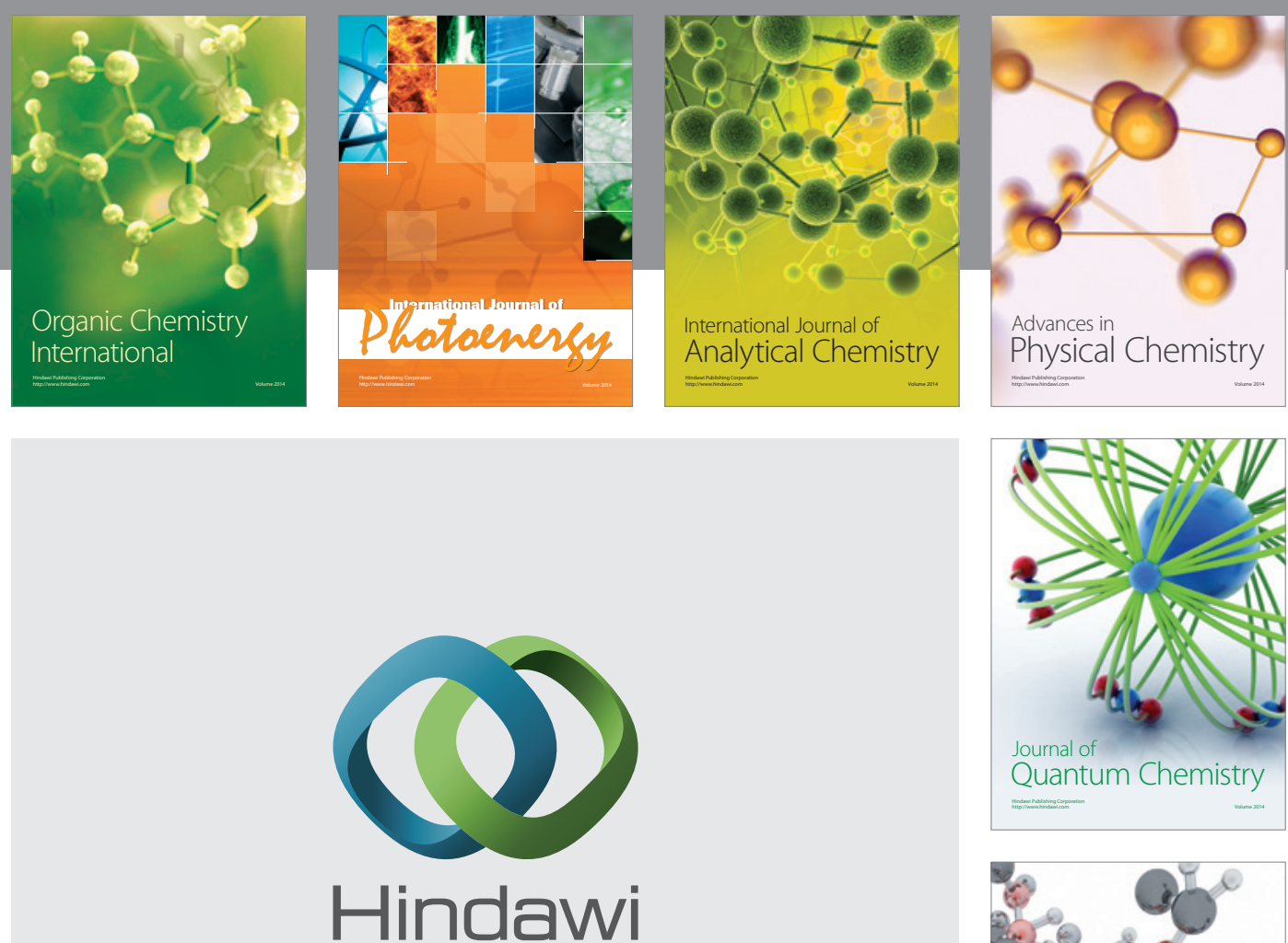

Submit your manuscripts at

http://www.hindawi.com

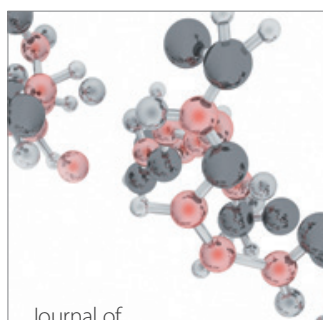

Analytical Methods

in Chemistry

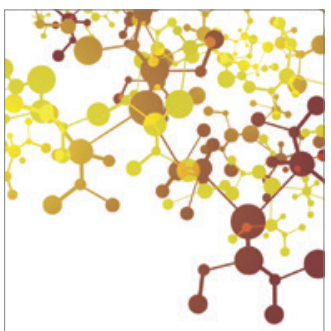

Journal of

Applied Chemistry

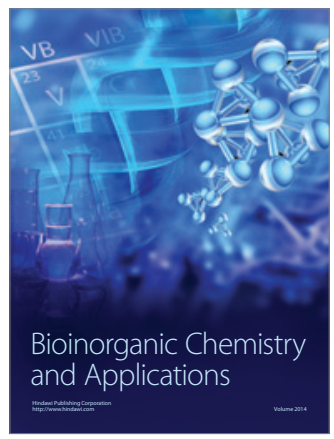

Inorganic Chemistry
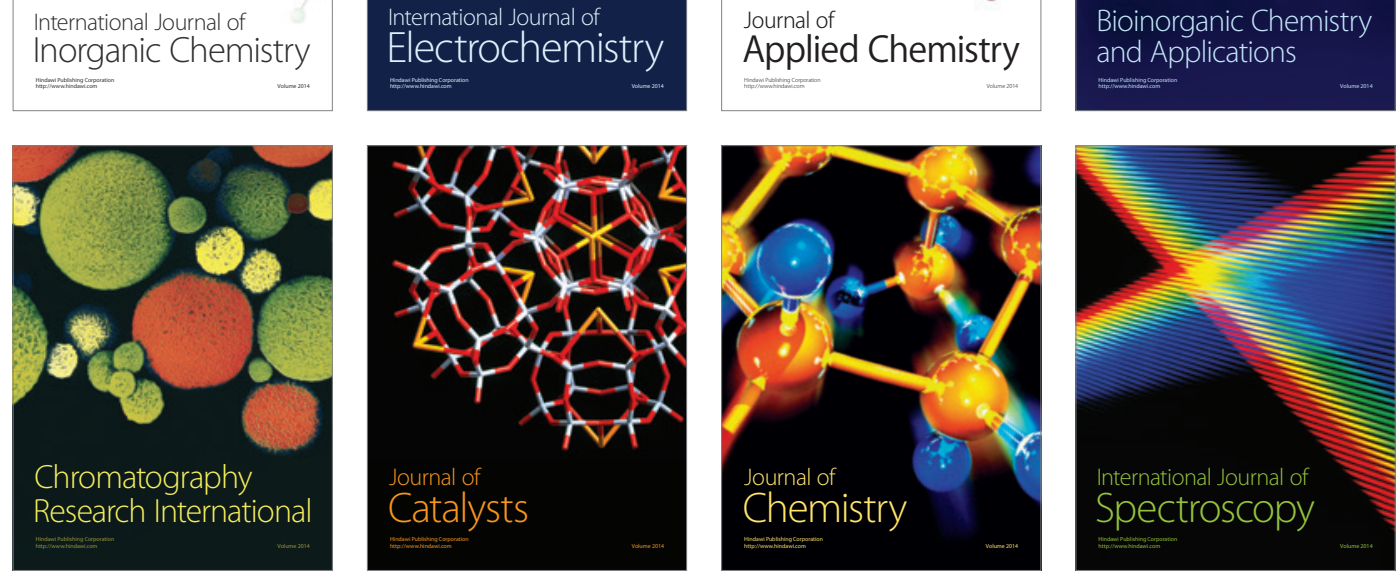